\title{
$\mathfrak{9} \mathfrak{n} \mathfrak{a} \mathfrak{l} \mathfrak{t}$
}

\section{Crites seft.}

Munbt's Gyftem ber \$gilojophie. 1. (Ebuarb von Gartmamn.). . . . Geite 1

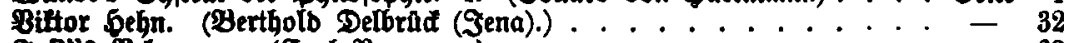

Suft's Bazquez. (Garl Reumann.) . . . . . . . . . . 63

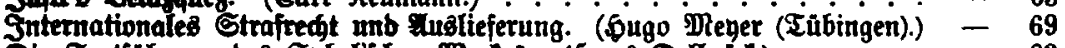

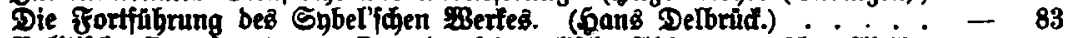

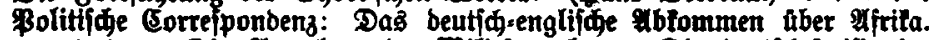

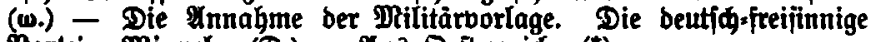

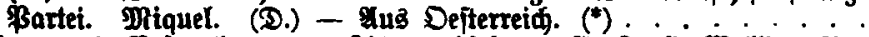

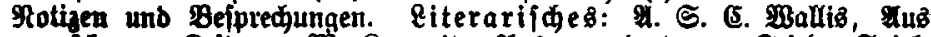

fumater Geit. - פi Sremnib, Iusgetwanberte. - Friebr. Spiel= Gagen, Stmber uno Erfinber. - Dof. Bulle, Dante's Beatrice im Reben und in ber Didytung. - Dr. 3 . Soopmam, Maffael=Stubien.

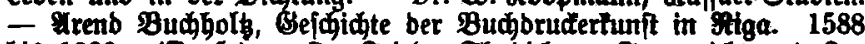
bis 1888. (D. 5.$)$ - Dr. Zriebr. Thubiфum, Femgerint und Sn: quifition. - Dr. Theob. Rinoner, Der angeblide urfprung ber Beme: getidte aus ber Inguifition. (Eomab ßormhaf.) .......

\section{3weites \$eft.}

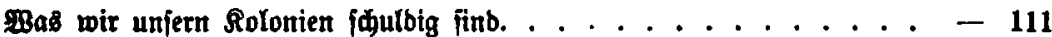

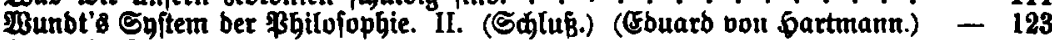

Goethe's Tagebăder. (Dtto Đarnađ̃.) . . . . . . . . . . - 153

Ein nađgeborener Junghegelianer. (Eonitantin $\Re$ joler.) . . . . . . - 165

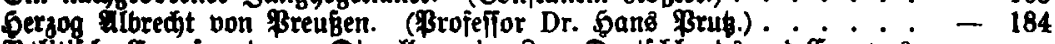

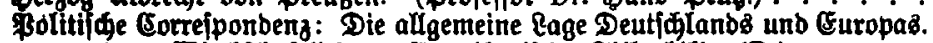

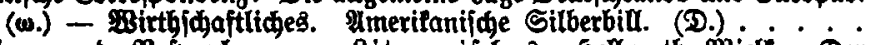

Nottzen und Beipredungen. Riterarifues: Ђellmuth Ditelfe, Der Deutife Roman bes 19. Jabrhunderta. - Rarl Reimbad, Die beut:

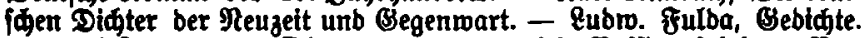

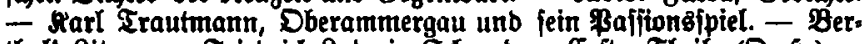
thold Ripmann, Friebrid Eubroig Sđaroeber. Eriter Theil. (D. \$.) Dlorib Earriere, Rebensbilber. $(-\pi-) \ldots . . . . .$.

\section{Drittes \$eft.}

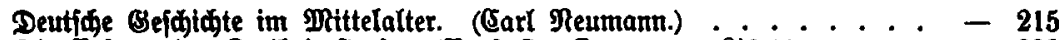

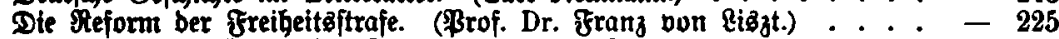
\$arum zaubert Gamlet? (Staatiantwalt Dr. Damme.) . . . . . . - 247

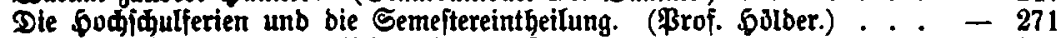
Die sacenton ber afabemifi gebildeten \&egrer. . . . . . . . - 278

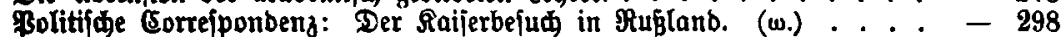
Rotizen unb Befprechungent. \ift orifde

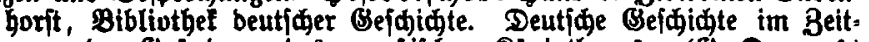

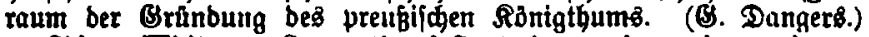
- Sidney Whitman, Conventional Cant, its results and remedy. Sulius Geibeman, Die Stefonnation in ber Dlart Branbenburg. (D.)

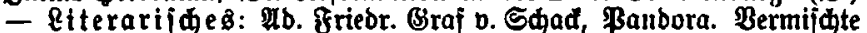

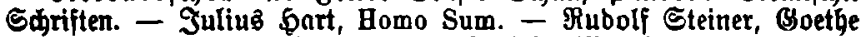

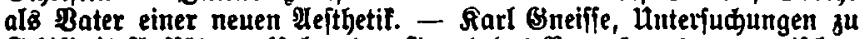

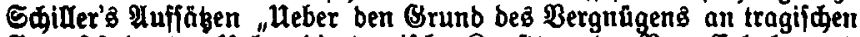
Gegenftänben", "Uleber bie tragifhe Runit" und "Bom Errbabenen". (D. ૬.)...................... 301 


\section{Biertes \$eft.}

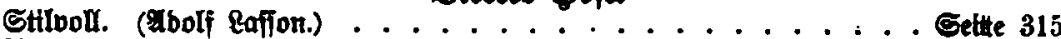

F्ă ein Bißmard. (Dr. Seturid \$3eber.) . . . . . . . . - 345

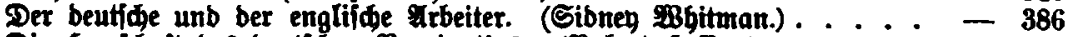

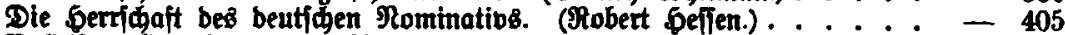

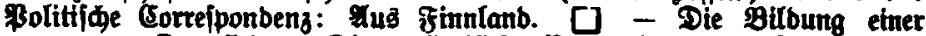
neuen Dppofition Die polizeifide Bebanblung ber Soctalbemo.

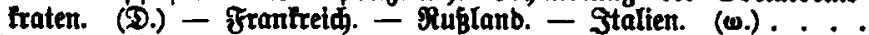

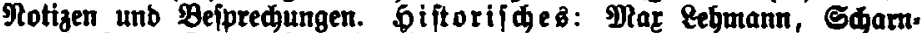
Gorft. - Friebr. Ptippolb, Erinnerumgen aus bem Reben bes Beneral. Felbmarf

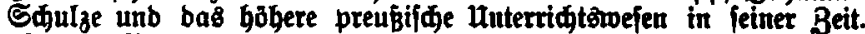
(D.) - \$ābagogijues: Dr. J. Beffden, \$. Süffelbt unb bie Sdule ber Zutunft. - Dr. Sirarbet: Breling, Die Nufgaben ber öfrentlichen Erziegung gegenüber ber pocialen Frage. - Dr. \$aul Eauer, Etaat uno Ergiehung. Squlpolitifde Bebenfen. - \$roj. Dr. Bujt. Bed, Bor ber Entideibung. Deinungen unb Bumide zur Swulreform. - Dr. Suling, Das Gnmnafium mit zebnjăhrigem Gurfus. - Dr. \&attman, Gine auşgleidenbe \&ōjung ber Reform:

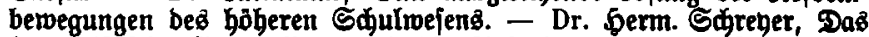
Gumanifitidge Gymnafium unb bie Anforberungen ber Begentaart. - Dr. Ud. Eaffon, Sint ut sunt. Ffar bas alte Bymnafum miber bie Reuerer. Stunf Thejen. - \$rof. Dr. Бerm. \$land, Das \&atei=

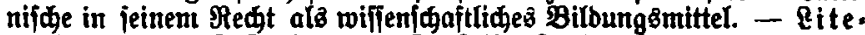
rarifues: Dr. \&. Trojt u. Dr. Ffr. Reift, Rönig DRarimilian II. von Bayern uno Sdjelling. Briefmedfel. - S. v. Dôninger, Briefe unb Erflärungen. 1869-1887. - F. \$eter, Das \$rieftererbe. (D. (⿹.)

\section{Fûftes seft.}

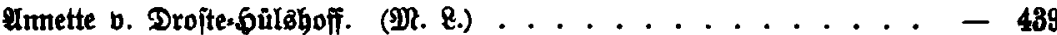

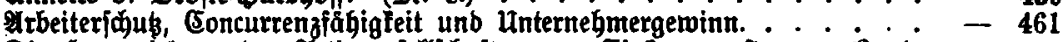

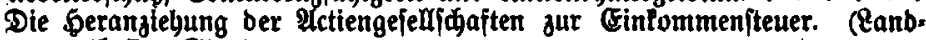
ratb Dr. Strub.) . . . . . . . . . . ... - 470

Bur Unterridtsfrage. (Eonftantin $\Re$ aßjer.) . . . . . . . . -482

Eine Petfe in's beilige Eanb im 4. Jahrhunbert. (\$rof. Dr. B. Arhger.) - 491

Brtefwedjel eines Theoretiterō unb eines \$rattiters aber Mrbeiterorgani: jation unb Streits. . . . . . . . . . . . .

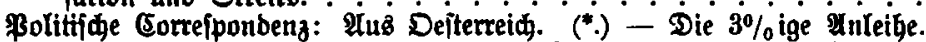

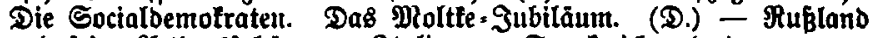

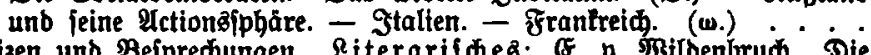

Notizen und Befpredungen. Riterarifdes: E. b. \$itbenbrud, Die Saubenlerche. - 5. Eubliner, $\mathfrak{I m}$ Spiegel. - 9 . Strinbberg, Der Bater. - Sarl Siegen, Ráthduen von Geilbronn. - Sugo v. Snebel. Doeberib, Sarl Rubntg v. Anebel. (D. G.) ......... - 530

Eechftes peft.

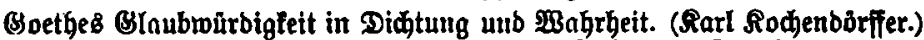
Pflidtexemplare und Fađbibliotheten. (Dr. Johannes Frante.) . . . .

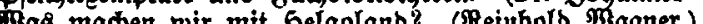

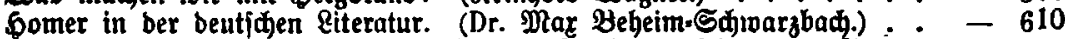
Bolitifhe Eorrefyonbenz: Die Entlafiung Etöders. Die neuen Steuer: Borlagen. (D.) - Rußlanb. - Stalien. - Frantreiđ. - Eng: lanb. (w.) . . . . . . . . . . . .

Motizen uno Befpredungelt. Riterarijdes: \$. Pinor, Shiller. Seln

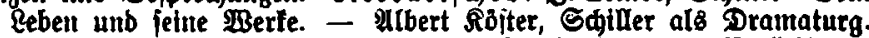
- Dtto Debrient, Boetbe's Bejhidte Bottfriebend oon Berlidingen mit ber eifernen Ganb. - 5. Subermann, Sobom's Gnbe. (D. ๖.)

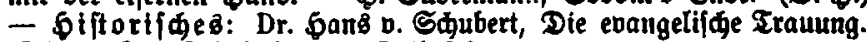
(D.) - Bur Squlteform. (Delbríd.) . . . . . . . . . 